\title{
TUBERCULOUS CAVITIES IN THE APEX OF THE LOWER LOBE
}

\author{
BY \\ JOHN CROFTON \\ From the Brompton Hospital
}

It has long been recognized that tuberculous cavities may occur in the apex of the lower lobe of the lung, often known as the dorsal lobe (Kidd, 1886 ; Fowler, 1888 ; Sweany and others, 1931). Steen (1945) has reviewed the many publications on basal tuberculosis, but no paper I have traced has been concerned exclusively with tuberculous cavities of the dorsal lobe; most authors do not differentiate between the various distributions of basal tuberculosis, though some (Reisner, 1935; Wiedman and Campbell, 1937 ; Cohen, 1945) have stated that in the majority of their cases the lesion was at the apex of the lower lobe.

In 18 publications quoted by Steen (1945) the incidence of basal disease averaged $1.5 \%$ of all cases of tuberculosis, varying from 0.15 to $18.3 \%$ in different papers. In a careful study with stereoscopic radiographs Sweany and his colleagues (1931) found that $13.7 \%$ of 268 " primary reinfection cavities" were situated in the apex of the lower lobe.

Almost all authors are agreed that basal tuberculosis is much commoner in women. This is attributed to the smaller respiratory excursion of the diaphragm (Reisner, 1935; Ossen, 1944). Lesions are reported most frequently on the right side of the chest, which is said to be due to the lesser movement of the right leaf of the diaphragm and the more vertical direction of the right main bronchus (Reisner, 1935), but it is possible that lesions on the left have often been missed because they are hidden behind the heart in the usual postero-anterior radiograph.

The prognosis of basal tuberculosis in general was formerly regarded as very poor (Kidd, 1886 ; Dunham and Norton, 1927). Since the introduction of artificial pneumothorax a less gloomy view has been taken by some writers (Reisner, 1935; Weidman and Campbell, 1937; Busby, 1939 ; Cohen, 1945), but the follow-up period in these reports has usually been brief and spreads of disease common. Hawkins and Thomas (1946) obtained poor results with artificial pneumothorax, but were impressed by the use of arti- ficial pneumoperitoneum combined with phrenic interruption.

As has been pointed out, none of these papers is exclusively concerned with tuberculous cavities in the dorsal lobe, but there is an impression that these cavities are peculiarly difficult to treat with artificial pneumothorax. The present study was undertaken in an attempt to refute or confirm this impression, and to examine whether dorsal lobe cavities have any clinical peculiarities which differentiate them from tuberculous cavities elsewhere in the lungs.

\section{Method of InVestigation}

All reports on radiographs taken at the Brompton Hospital over the ten-year period 1935-44 inclusive were studied. Where the report suggested a dorsal lobe cavity the radiographs were examined. Cases were only admitted to the series if the cavity was demonstrated to be in the dorsal lobe by a lateral film, by tomograms or, occasionally, by bronchograms. Only those cases were included in which the dorsal lobe cavity was the dominant lesion from the therapeutic point of view and which were admitted to the Brompton Hospital in the first instance. It will be realized that the number of cases which could be included in the series is a gross underestimate of the actual incidence. In order to assess the results of treatment a follow-up period of at least three years after the institution of the final method of collapse therapy was demanded; the average was 6.0 years. Fiftyfour cases satisfied these criteria. In one of these there were bilateral dorsal lobe cavities. In a further 10 cases the follow-up period was inadequate.

Clinical Characteristics.-In order to investigate whether tuberculous cavities in the dorsal lobe have any particular clinical characteristics, the 54 cases with dorsal lobe cavities were compared with a control series of 54 cases with tuberculous cavities elsewhere. It was arranged that the control series had the same sex distribution, but otherwise the cases were taken at random from the records of 
the hospital. The following characteristics were compared in the two groups: age distribution, the side on which the lesion was situated, the presence of cough and sputum, haemoptysis, pain in the chest, physical signs in the chest, and the ease with which a positive sputum was obtained. The figures for all these characteristics, except two, were similar in each series. The two points on which there was dissimilarity were the side of the lesion and the incidence of pain in the chest. Of the dorsal lobe cavities $18(33 \%)$ were on the left, 35 $(65 \%)$ were on the right, and in one case there was a cavity in the apex of each lower lobe. Of the cavities in the control series $25(46 \%)$ were on the left, $25(46 \%)$ on the right, and four $(8 \%)$ were bilateral. Taking the cases in each series in which the cavity was unilateral, the differences in distribution, though suggestive, are not statistically significant by the usual criteria $\left(\chi^{2}=2.1 ; P=0.2-0.1\right)$.

Thirty-two (59\%) of the patients with dorsal lobe cavities had had pain on the side of the lesion when first seen, as compared with $22(41 \%)$ of the control group. This difference, though again suggestive, is not statistically significant $\left(x^{2}=3.0\right.$, $\mathrm{P}=0.1-0.05$ ).

Results of Treatment.-The dorsal lobe cavity was regarded as having closed if the following criteria were satisfied.

1. The case had been followed up for at least three years after the institution of the last measure of collapse therapy.

2. There were no significant symptoms.

3. The sputum was consistently negative (usually to direct examination of a smear only).

4. The cavity appeared to have closed radiologically. It must be stated, however, that only a minority had tomograms after collapse therapy was begun.

5. There was no radiological evidence of spread of the disease to fresh areas of the lung.

TABLE I

ANalysis of Cavity Ċlosure in 55* Tuberculous Cavities of the Dorsal Lobe

\begin{tabular}{c|c|c|c|c|c|c|c|c|c}
\hline \multicolumn{2}{c|}{ Cases Treated by Artificial Pneumothorax } & \multicolumn{3}{|c|}{ Cases Treated by Methods other than Artificial } \\
Pneumothorax
\end{tabular}

* Series of 54 cases, one with bilateral dorsal lobe cavities. 
The results of the various methods of treatment are analysed in Table I. The cases are grouped according to the final treatment adopted in each instance.

It will be seen that $33(60 \%)$ of the total of 55 cavities were closed by artificial pneumothorax, either alone or supplemented by adhesion section, interruption of the phrenic nerve, or both. Of the 44 cavities for which artificial pneumothorax, alone or in combination, was the final treatment $75 \%$ were closed. In six cases artificial pneumothorax was attempted and either no space was obtained or the pneumothorax was abandoned as unsatisfactory shortly after induction. If these cases are added to the total, the figures shown

TABLE II

Analysis of 50 Dorsal lobe Cavities Treated by Artificial PNeumothorax

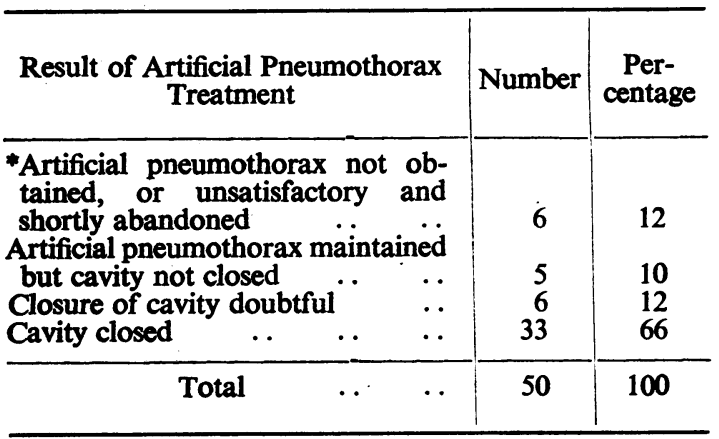

- In 4 of the cases in which artificial pneumethorax was either not obtained or abandoned shortly as unsatisfactory the cavity was subsequently closed by other collapse measures; by thoracoplasty combined with phrenic interruption in 2 cases, by thoracoplasty alone in 1 case, and by basal extrapleural pneumothorax in 1 case.

in Table II are obtained. It will be seen that in $66 \%$ of the cases in which artificial pneumothorax was attempted the cavity was closed.

Cases of Doubtful Cavity Closure.-Thesix cases in which cavity closure was doubtful had all been treated by artificial pneumothorax. In five closure was regarded as doubtful because, although there was no radiological evidence that the cavity had persisted, the disease later spread to a fresh area of the lung. In the sixth case the sputum was found to be positive six years after induction of the artificial pneumothorax, although tomograms showed no evidence of a persistent cavity.

Failures. - The 10 cases in which the cavity failed to close are analysed in Table III. There were five deaths, one from steady deterioration with an open cavity, two with tuberculous empyema, one after operation, and one from status asthmaticus.
TABLE III

analysis of Cases in which Dorsal lobe CavtTy REMAINED UNCLOSED

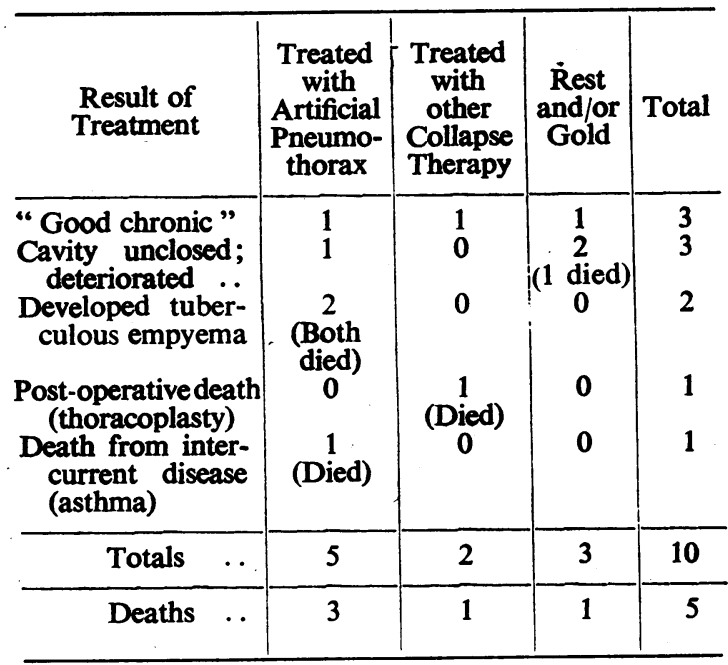

Adhesion Section.-As can be seen from Table I adhesion section was done in 20 cases, in 16 of which the cavity was closed. In an attempt to estimate whether any cases might have benefited from a thoracoscopy which was not in fact done, I have analysed the cases in which some sort of an artificial pneumothorax was obtained but in which this failed to close the cavity. These total 11 cavities. In only four cases out of the 11 was no thoracoscopy done. In two of these the artificial pneumothorax was replaced by a basal extrapleural pneumothorax ; in one, although the cavity appeared radiologically to close, a tuberculous empyema later developed; and in the fourth the cavity remained unclosed and the artificial pneumothorax was later abandoned. There can therefore be little grounds for suggesting that thoracoscopy was not resorted to sufficiently often, even though, in the presence of a dorsal lobe cavity, posterior adhesions will frequently be invisible on the postero-anterior radiograph.

Incidence of Pleural Effusion.-The incidence of pleural effusion in the 44 cases treated by artificial pneumothorax is recorded in Table IV. Effusion of some degree was noted in $43 \%$. This is almost certainly an underestimate, as minor degrees of effusion were probably not mentioned in followup reports. Effusion of sufficient clinical importance to warrant aspiration or alteration in managèment occurred in $25 \%$. This figure is probably accurate. It includes three cases developing tuberculous empyemata. Of these, two died; in the 
TABLE IV

INCIDENCE OF EFFusion IN 44 CASES OF DORSAL LOBE Cavity Treated With artificial PNeUmothorax

\begin{tabular}{|c|c|c|}
\hline Category of Effusion & $\begin{array}{c}\text { Number } \\
\text { of } \\
\text { Cavities }\end{array}$ & $\begin{array}{l}\text { Percentage } \\
\text { of Total } \\
\text { Artificial } \\
\text { Pneumo- } \\
\text { thoraces }\end{array}$ \\
\hline $\begin{array}{l}\text { Developed tuberculous empyema } \\
\text { Effusion of some clinical signifi- } \\
\text { cance (aspirated, necessitated } \\
\text { increased rest, etc.). } \\
\text { Effusion incidental and of no } \\
\text { clinical importance .. } \\
\text { No significant effusion recorded; } \\
\text { case followed throughout } \\
\text { course } \ldots \text {.0. } \\
\text { No effusion according to follow- } \\
\text {.up reports but detailed re- } \\
\text { cords not available .. }\end{array}$ & 16 & 20 \\
\hline Total .. & 44 & 100 \\
\hline
\end{tabular}

third the artificial pneumothorax was abandoned, the patient became free from symptoms, and the cavity remained closed under a cap of tuberculous pus. In this, and in one other case, the effusion seemed to contribute to the closure of the cavity.

Unsuccessful Follow-up. - It could be argued that the figures for the results of treatment by different forms of collapse might be vitiated by the 10 cases in which follow-up was unsuccessful. These cases were therefore analysed as far as follow-up was available. All had been treated with artificial pneumothorax and in only two was the cavity unclosed at the time of the last report. The figures for cavity closure by artificial pneumothorax are therefore more likely to have been increased than decreased if these cases had been followed up for the full three years.

Comparison with Results of A.P. for Lesions Elsewhere.-I have not been able to find a report concerned exclusively with the results of artificial pneumothorax for tuberculous cavities in the upper lobe. Bloch and others (1941) have reviewed the world literature on the results of artificial pneumothorax treatment of pulmonary tuberculosis. I have abstracted from their tables figures from articles published during the five-year period 1935-9. In 16 publications 3,022 cases are reported in which the standards of "cure" were regarded as acceptable, the follow-up period including observation after re-expansion of the artificial pneumothorax ; of these cases $45 \%$ were classed as cured or fit. Of 4,257 cases, reported in eight articles, in G* which the follow-up period was four to five years, but in not all of which re-expansion had taken place, $22.5 \%$ were regarded as cured or fit.

In Hjaltested and Törning's (1939) series of 95 cases with cavities, $55 \%$ were well after a followup period of at least three years, though $38 \%$ were dead. It will be seen that the results, here reported, of artificial pneumothorax treatment for dorsal lobe cavities compare favourably with those reported elsewhere for pulmonary tuberculosis in general.

As regards the incidence of effusion, Eglee and Jones (1937) found that effusion sufficient to aspirate developed in 74 of 100 cases of pulmonary tuberculosis of all types treated with artificial pneumothorax and in eight the effusion was purulent. Aycock and Keller (1939) report an effusion rising above the dome of the diaphragm in $37.5 \%$ and tuberculous empyema in $5.3 \%$ of 530 cases. This may be compared with an incidence in the present series of clinically important effusion in $25 \%$, including the three cases $(5.5 \%)$ which developed tuberculous pus.

\section{Discussion}

It must be realized that the cases discussed were those in which the dorsal lobe cavity was the dominant lesion, which in most cases implied that it was the only significant lesion. This partly accounts for the relatively high proportion of cases with a successful outcome, in spite of the fact that many were treated in London under wartime conditions. It is possible that, with the increasing use of artificial pneumoperitoneum, a contemporary series might show even better results. Nevertheless there is a danger that the use of artificial pneumothorax for these cases may be too readily abandoned in favour of artificial pneumoperitoneum. The latter may prove to be the treatment of choice, but this has not yet been established by adequate follow-up studies. In the series here presented, of those dorsal lobe cavities for which artificial pneumothorax was attempted, this was successful, alone or in combination with phrenic interruption, in as high a proportion as $66 \%$. It therefore seems reasonable to suggest that in most cases artificial pneumothorax should be attempted and that, as posterior adhesions may not be easily visible in the radiograph, a routine thoracoscopy should be done even if the pneumothorax seems satisfactory. The cavity should not be regarded as closed unless no cavity can be seen in tomograms. With these precautions artificial pneumothorax should be successful in a large proportion of tuberculous cavities in the dorsal lobe. 


\section{SUMMARY}

1. A series of 54 cases is analysed in which a tuberculous cavity of the apex of the lower lobe was the dominant lesion. In one case there was a cavity in the apex of each lower lobe. These cases were admitted to the Brompton Hospital during the ten-year period 1935-44 and were followed up for at least three years.

2. In accordance with the usual experience in basal tuberculosis, most of the patients were women.

3. Comparison of clinical characteristics with a control group with tuberculous cavities elsewhere showed no statistically significant differences in age distribution, the side on which the lesion was situated, the presence of cough and sputum, haemoptysis, pain in the chest, physical signs in the chest, or the ease with which a positive sputum was obtained. Nevertheless in the series of dorsal lobe cavities the lesion was suggestively commoner on the right side and pain was a more frequent symptom than in the control series.

4. In $66 \%$ of cases in which artificial pneumothorax was attempted the cavity was successfully closed by artificial pneumothorax alone, or in combination with adhesion section or phrenic nerve interruption, or both.

5. Pleural effusion and tuberculous empyema were no more frequent than in artificial pneumothorax for pulmonary tuberculosis elsewhere in the lung.
6. It is suggested that in most cases with dorsal $\overrightarrow{\vec{S}}$ lobe cavities artificial pneumothorax should be $\overrightarrow{0}$ tried. Thoracoscopy should be done as a routine $\frac{C}{0}$ and the cavity should not be regarded as closed until it can no longer be demonstrated in $\widetilde{\Phi}$ tomograms.

I am most grateful to the physicians of the $\vec{P}$ Brompton Hospital for their courtesy in allowing me to analyse their cases, and to Dr. F. H. Young, $\overrightarrow{\vec{J}}$ Dr. J. G. Scadding, and Dr. Howard Nicholson for ${ }^{\circ}$ helpful criticism. Dr. D. A. Mitchison kindly checked my statistics.

\section{REFERENCES}

Aycock, G. F., and Keller, P. E. (1938). Amer. Rev. Tuberc., 38, 277.

Bloch, R. G., Tucker, W. B., and Adams, W. E. (1941). 옥 J. thorac. Surg., 10, 310.

Busby, L. F. (1939). Amer. Rev. Tuberc., 40, 692.

Cohen, R. C. (1945). Brit. med. J., 1, 662 .

Dunham, K., and Norton, V. V. (1927). J. Amer. med.

Ass., 89, 1573.
Eglee, E.P., and Jones, O. R. (1937). Amer. Rev. Tuberc., $\vec{\oplus}$ 35,500 .

Fowler, J. K. (1888). The Localisation of the Lesions of Phthisis. London.

Hawkins, F. S., and Thomas, G. O. (1946). Tubercle, Lond., 27, 82.

Hjaltested, O., and Törning, K. (1939). Brit. J. Tuberc., 33,4 .

Kidd, P. (1886). Lancet, 2, 615.

Ossen, E. Z. (1944). New Engl. J. Med., $230,693$.

Reisner, D. (1935). Arch. intern. Med., 56, 258.

Steen, P. (1945). Brit. J. Tuberc., 39, 3.

Sweany, H. C., Cook, C. E., and Kegerreis, R. (1931). Amer. Rev. Tuberc., 24, 558.

Weidman, W. H., and Campbell, H. B. (1937). Amer. Rev. Tuberc., 36, 525. 